Aytaş, G. (2017). Kuramsal ve işlevsel dil öğretiminde tiyatronun rolü ve önemi. Ana Dili Eğitimi Dergisi, 5(4), 854-860.

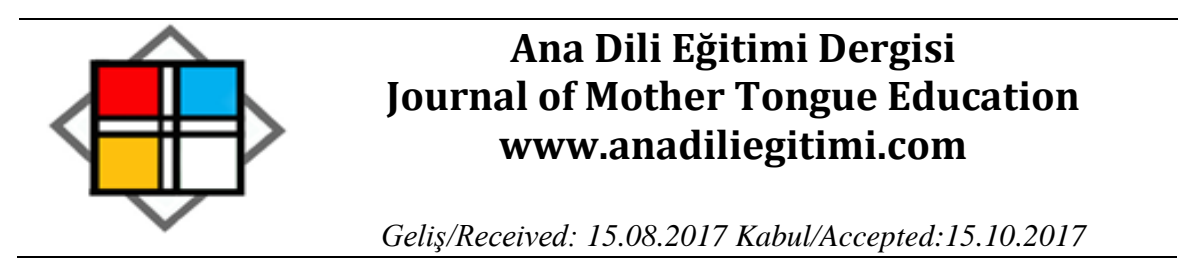

\title{
Kuramsal ve İşlevsel Dil Öğretiminde Tiyatronun Rolü ve Önemi
}

Gıyasettin AYTAŞ*

\section{Öz}

Tiyatro bir sanat faaliyeti olmanın yanında etkili bir iletişim aracıdır. En eski dönemlerden bu yana, hatta insanlığın varlığından itibaren tiyatrodan ve onun etkililiğinden söz etmek olasıdır. Dil edinim süreçleri ile ilgili görüşler birbirinden farklı olmakla birlikte, dilin kullanımında en temel gösterge iletişim ihtiyacıdır. Bununla birlikte dil aynı zamanda bir temsil göstergesidir. Onun aracılığı ile aidiyet ve mensubiyetler hakkında hüküm verilir. Bireyin sosyal ve siyasal özelliklerinin yanında, karakteristik özelliklerini de kullandığı dil aracılığı ile tespit edebilmekteyiz. Tiyatro bu farklılıkların her birini bir arada sergileyen ve somut bir göstergeye dönüştüren bir araç olarak karşımıza çıkmaktadır. Tiyatro yaşanmışlıkları bir araya getirerek iletişim çeşitliliğini ve zenginliğini ortaya koyar. Hayatın hem var olanını hem de olması gerekenlerini birlikte sunar. Her ne kadar bir durum veya olay sonsuz olarak değerlendirilmesi mümkün değilse de tiyatro bu mümkün olmayana varsayımlar açısından yaklaşır. İnsan davranışlarının bilinçli ve bilinçsiz olmak üzere iki göstergesi bulunmaktadır. Bu iki durumla ilgili iletişim yeterliliklerini ve farklılıklarını tiyatro aracılığı ile birlikte görebiliriz. Güzel sanatların hemen tamamını bir arada ve birlikte içinde barındıran tiyatro, bütün dil aşamaların birlikte ve bir arada sunar. Hem iç hem de dış konuşmanın bütün inceliklerini birlikte sunan ve bu özelliği ile karşılıklı ifade çeşitliliğini tiyatro birlikte sunar. Iletişim ve dil ediniminde tiyatronun önemini ve gerekliliğini anlamak ve sorgulamak için tiyatronun işlevsel özelliğinden bütün ayrıntıları ile yararlanmak kaçınılmazdır.

Anahtar kelimeler: tiyatro ve dil, dinleme, konuşma, konuşma sanatı, güzel ve etkili konuşma, iletişim

\section{The Role and Importance of Theater in Theoretical and Functional Language Teaching}

\begin{abstract}
Besides being an art from, theater is also a tool for communication. It is possible to trace theater and its effectiveness back to the earliest periods, even to the emergence of mankind. The opinions about the processes of language acquisition are different from each other, but the most basic indicator in language use is the need for communication. In the meantime, language is an indicator of representation. Through language, judgments are made about a person's belonging and affiliation. In addition to the social and political characteristics of an individual, we can also identify his characteristics through the language he uses. Theater emerges as a tool that displays each of these differences together and transforms them into a concrete indicator. By piecing experiences together, theater presents the variety and richness of communication. It presents both what exists and what should exist in life. Although a situation or event cannot be regarded as infinite, theater approaches the impossible in terms of assumptions. Human behaviors have two indicators as conscious and unconscious. We can see the communicative competences and differences in these two situations through theater. Theater, which contains almost all of the fine arts together and houses them within itself, offers all language stages together. Presenting all the subtleties of both internal and external speaking, theater presents this feature and diversity of mutual expression together. In order to understand and inquire about the importance and
\end{abstract}

\footnotetext{
*Prof. Dr., Gazi Üniversitesi, Gazi Eğitim Fakültesi/ Türkçe Eğitimi Anabilim Dalı, giyaytas@gazi.edu.tr.
} 
necessity of theater in communication and language acquisition, it is inevitable to utilize its functional characteristic in its entirety

Keywords: theater and language, listening, rhetoric, oratory, communication

\section{Giriş}

Duygu, dilek ve düşüncelerin anlatımında farklı araç ve yöntemlerden yararlanılmaktadır. Bu yöntemler arasında hem gösterme hem de anlatmayı bir arada ve etkin kullanan tiyatro, bir gösteri sanatı olmanın ötesinde, sosyal gelişim ve kişisel eğitimin de önemli araçlarından biridir. Bütünsel olarak iletişime ait bütün unsurları, bir arada ve birlikte gerçekleştirme fırsatını sunan tiyatro, dil becerilerinin etkin ve verimli kullanımının aracı olmanın yanında, bu becerilerin geliştirilmesine de aracilık eder.

Dil becerilerinin geliştirilmesine yönelik çalışmalar ve bu yönde hazırlanan programlar yeni arayışları da beraberinde getirmektedir. Bu arayışların gerekçesi, dilin her aşama ve seviyede kullanım yeterliliğini en üst seviyeye çıkarmaktır. Bu yüzden tiyatronun bu yeterlilikte rolünün belirlenmesi önem kazanmaktadır.

Bilindiği gibi, karşılıklı iletişimde, farkında olalım veya olmayalım duruma ve zamana uygun bir role bürünmekte ve bu role uygun konuşmalar yapmaktayız. Böylece, tiyatronun dille olan bağlantısı kendiliğinden gerçekleşmektedir. Bunun daha sistemli ve bilinçli bir hâle getirilmesi durumunda, aktif ve etkili dil kullanımı daha üst seviyede olacaktır. Dolaylı veya doğrudan gerçekleştirilen dil etkinlikleri, dil ve iletişim gerekçelerini sistemleştirir. Bu oluşturma süreçlerinin uygulama alanını en belirgin bir şekilde tiyatro aracılığı ile gerçekleştirmekteyiz. İster yazılı, ister sözlü olsun tiyatro metinleri, her şeyden önce işlevsel ve iletişimsel dil özelliklerinin bütün unsurlarını kendi içinde barındırır.

Edebî metinlerde dilin kullanım tercihi değişebilmektedir. Özellikle tiyatro eserlerinde dil tercihi diğer türlerden daha çok değişkenlik gösterebilmektedir. Eserin konu ve içeriğine bağlı olarak dilin kullanımı edebî olduğu gibi, günlük dilin özelliklerini te taşıyabilmektedir. Bu yönüyle tiyatro, dile ait unsurların tamamını bir arada ve bütün olarak uygulanmasına fırsat vermektedir.

\section{Kuramsal ve İşlevsel Olandan Ne Anlamalıyız?}

Bir bilim alanından söz edildiğinde, o bilim alanını ilgilendiren kuramlardan da söz etmek gerekmektedir. Bilim kendi içinde bir felsefeyi barındırdığına göre, kuram da bu felsefenin işlerliğini ve geçerliliğini ortaya koyar. Bir kuramın bilimsel olabilmesi için onun öncelikle işlevsel olması gerekmektedir.

Genel olarak kuram, bir gerçekliği açıklamak için olay, olgu ve nesneler arasında düzenli ilişkilerden genel sonuçlar çıkarma ve bu sonuçlara göre çerçeve çizmektir. Kuram, sosyal bilimler 
alanında genel önermeler için kullanılmakta, fen bilimlerine göre kesin yargılar içermemektedir. Ana hatlarıyla bir kuramdan söz edebilmek için kuramın birbiri ile tutarlı, geçerli ve uygulanabilir bir nitelikte olması gerekmektedir.

Bir bilim alanında kuramsal yaklaşımdan söz ederken, detaylandırma ve dağıtma yerine toparlama ve ilkeleştirme esas alınır. Bu yüzden, özellikle sosyal bilimlerin temel araştırma süreçlerinde kuramsal yaklaşımlar önemli bir yer tutmakta, özellikle dil öğretiminde kuramsal yaklaşımların önemi ve gerekliliği daha büyük bir önem kazanmaktadır.

Bir şeyin kuramsal olması durumunda, onun aynı zamanda işlevsel olması da beklenir. İşlevsel olma, kullanılabilir, teorinin ötesine geçerek uygulanabilirlik ilkesine sahip olma durumudur. Son yıllarda bilgi aktarma ve bilginin öğretiminde işlevsel olmasına özen gösterilmektedir. İşlevselliğin gösterge olarak ortaya konulabilmesi için modelleme yapılması gerekmektedir. Özellikle dil öğretim uygulamalarında bu modellemelerin yeterince yapılamadığı ve bu yüzden de teorik bilgilerin önemli bir kısmı unutulup gitmekte ve zamanla tekrarlanmak zorunda kalınmaktadır. İşte bu bağlamda tiyatro, dilin işlevsel kullanımına yönelik bir modelleme sunmaktadır.

\section{Tiyatronun Dil Becerilerine Etkisi}

Tiyatro, insan için ve insanca yapılan bir sanat olduğundan, insanın iç dünyasının birikimlerini dışa vurmasında en etkili iletişim aracıdır. Bir diğer ifade ile tiyatro dili bilinen ve algılananın ötesine taşıyarak ona farklı dünyaların ve duyguların bir arada kullanıldığı bir değer katar. Bireysel olanın yanında, toplumsal algının da bir arada yansıtıldığı tiyatroda, insanın varlık alanlarının tamamını bir arada bulma imkânı elde edilir. İnsanla birlikte iletişim var olduğu ve bir ihtiyaç olduğuna göre, tiyatro da bu sürecin ilk aşamasından itibaren var olmuş ve olmaya da devam etmektedir.

Bireyin dil edinim süreçleri ile ilgili ileri sürülen birbirinden farklı görüşler bulunmakla birlikte, bu görüşlerin hemen tamamı dilin temel amacının bildirişim olduğu üzerinde ittifak ederler. İnsanın kendini anlatmak ve anlamak ihtiyaçlarının sonucu olarak gelişen dilin oluşma ve olgunlaşma sürecinde, bireylerin ilgi ve ihtiyaçlarının yanında, kimlik ve kişilik özellikleri de etkilidir. Özellikle millî kimliğe bă̆lı dil edinim süreci ile yerel özellikler çerçevesinde gelişen dil, birbirinden farklı olmakla birlikte, bunlar ortak dilin değişik kullanımlarını ortaya koyar. Her ne kadar bunların edinimi farklı süreçlere tabi olsa da dilin kullanım zenginliğine ve çeşitliliğine zemin hazırlar.

Dilin kullanım gerekçeleri içiresinde iletişim ilk sırada yer alırken, bu iletişimde algı dünyasını biçimlendiren ve onu yönlendiren unsurlar da etkili olmaktadır. Özellikle insanın etrafında olup bitenleri öğrenmek, bunlar hakkında değerlendirme yaparken algı yeterliliği önemli role sahip olur. Algı yeterlilikleri, hem dil hem de üslupta yardımcı ve etkili olur. 
Günümüzde en çok tartışılan konular arasında "dil bir temsil yeterliliğine ne kadar sahiptir?" İster bireysel olsun, ister sosyal ve toplumsal katmalar açısından olsun, dilin mutlak şekilde bir temsil özelliğine sahip olduğu açıktır. Bu temsil özelliğinin çeşitliliği ve gerekliliğini bir arada görmek ve algılamak çoğu zaman mümkün olamamaktadır. Kimi zaman bireyin içinde bulunduğu sosyal ve psikolojik şartların getirdiği sonuçlar, onun kendini ifade ederken kullandığı dile yansımaktadır. İşte bu ifade biçimi, hem dilin kullanım niteliği ve çeşitliliğini göstermekte hem de bireyin içinde bulunduğu durumu ortaya koymaktadır.

Kimi zaman dile ait unsurların kullanım gerekliliklerinde farklılaşmalar görülebilir. Bu farklılaşmaları bir arada ve bütün olarak ele almak ve aralarındaki ilişkileri değerlendirmek için öncelikle dilin belirleyicilerini tespit ve tasnif etmek gerekmektedir. Bunların yapılabilmesi için öncelikle ilk dönemlerden başlamak üzere dile ait verilerin kendi içinde oluşan ve olgunlaşan yapılarını ve ilişkilerini bir arada tiyatro aracılığı ile görmekteyiz.

Dilin kullanım gerekçesi ve gerekliliği, kullanıcısının sosyo-kültürel seviyesinin yanında, eğitim durumunu da ortaya koyar. Bu verilerden yola çıkarak, dil bir sosyal gösterge olma özelliğine sahip olur. Toplumun farklı kesimlerinde ve sosyal sınıflarında kullanılan dil bir gösterge unsuru olmasının ötesinde, sınıfsal bir yapıyı da belirler. Bu belirlemede kimi zaman taklit, kimi zaman da tekrarlar sayesinde bir gruba tabi olan bireyin, kendi yaşama alanını ve sınıfını da belirlemiş oluruz. Tiyatro, bütün sosyal sınıfları ve grupları birlikte, bir oyun sahnesinde bir araya getirerek farklıılıkları somutlaştırmanın yanında, ortaklıkları da belirgin bir hâle getirmektedir. Kimi zaman ağız özelliklerinde ortaya çıkan bir ifade biçiminin standart dille olan farklılıklarını ve bu farklııktan kaynaklanan yanlış anlamaları ancak tiyatro sayesinde somutlaştırabilmekteyiz. Bunun en eski ve etkili örneklerini, geleneksel tiyatromuz olan Orta Oyunu ve Karagöz'de görebilmekteyiz.

Bir sanat faaliyeti olarak karşımıza çıkan tiyatro, insanoğlunun gerçek hayatının ve gerçekliğinin gibileştirilmesinin bir aracıdır. İnsanoğlu günlük hayatında yaşadıklarını çoğu zaman yeterince gözlemleyememekte, kendi yaptıklarının farkında olamamaktadır. Bunların önemli kısmını da alışkanlık olarak değerlendirmektedir. Tiyatro sahnesinde, günlük hayatta karşılaştığımız ve farkında olmadığımız durumlar izleyiciye sunularak hem davranışlar hem de davranışlara bağlı kullanılan dili işlevselliği somutlaştırılır.

Edebî metinler, yazııma gerekçelerine bağlı olarak tür olarak adlandırılmaktadır. Her biri, bir diğerinden bu gerekçeye bağlı olarak farklılık gösterir. Türün özelliğine bağlı olarak sanatsal bir nitelik gösteren metinler, kimi zaman da gündelik olan bir dil tercihi ile karşımıza çıkabilmektedir. İşte bu metinler arasındaki ilişkileri ve farklılıkları incelemek, edebîlik özelliklerini bir kenara bırakacak olursak, dilin kullanım gerekçesi ve gerekliliğini de anlamamızı sağlar. Metinlerin dil özellikleri, yazarın 
niteliğini ortaya koymasının yanında, kullanılan dilin hitap ettiği sosyo-kültürel yapıyı da belirler. Kullanılan dilin karşılaştırıması, metnin değerini belirlemenin yanında, bir dilin gelişmişlik düzeyini görmemizi de sağlar.

Tiyatro, güzel sanatların hemen tamamını bir arada ve birlikte kullanmaktadır. Bu özelliğinden ötürü, diğer edebî türlerden farklı olarak yaşanılan gerçekle izleyeni yüzleştirmenin yanında, onu gerçek olandan uzaklaştırarak farklı bir dünya içine sokar. Bu açıdan bakıldığında tiyatro, oldukça farklı ve etkili bir rol üstlenir. Bireyin kendiyle yüzleşmesini sağlamanın yanında, kendisini sorgulamasına fırsat verir. Bu yapısıyla tiyatro, insanın yeni bir hayat serüvenine dâhil olup kendisini denetlemesine firsat verir.

Hayatın kendine özgü bir felsefesi bulunmaktadır. Bizler kimi zaman içinde yaşadığımız hayatı çoğu zaman müdahale etmeden ve denetlemeden yaşarız. Buna hayatın normal akışı diyerek genelleştiririz. Aslında insanoğlunun iradesi çoğu zaman bu kontrolü yapma çabası içine girse de çoğu zaman başarılı olamaz. İşte tiyatro, insanın iradesi ile kontrol edemediği veya bir nevi varsaydığı hayatın değişik sahnelerinden derlediklerini bize sunarak gözden kaçırdıklarımızı görmemizi sağlar. Bu sunum davranışsal olduğu kadar sözel ifadenin değişkenliğini de yansıtır. Aslında kuramsal olarak ifade edilmesi kolay gibi görünen dil ve dile bağlı davranış ilişkileri, tiyatro aracılığı ile basitin içindeki derinliğiyle birlikte anlamlı olmaktadır. Hayat da tiyatro gibi bir oyundur ve belli bir zaman diliminde sona erecektir.

Aslında insanın kendini ifade etmek için rol yapmak doğasında vardır. Kimi zaman başkalarının verdiği rol, kimi zaman da kendisinin yüklendiği rol bu davranışlarda belirleyici olmaktadır. İlk çocukluk dönemlerinden itibaren gelişen ve değişen roller, dilin kullanımında da belirleyici bir etkileme gücüne sahiptir.

Davranış bilimciler, insanın denetlenebilen davranışları ile denetlenemeyen davranışları arasındaki ilişkiler üzerinde çeşitli incelemeler yapmışlardır. Bu incelemeler sonucunda, denetlenemeyen davranışların sorumluluk duygusu daha az, denetlenebilen davranışlarda ise rol becerisi ile birlikte sorumluluk duygusunun daha üst düzeyde seyrettiği görülmektedir. İşte tiyatro aracılığı ile denetlenemeyen söz ve eylemlerin doğurduğu sonuçlar daha iyi anlaşılmakta ve bunların doğurduğu olumsuzluklar sorgulanabilmektedir.

Aslında tiyatro bir dil becerisi olarak ele alındığında, birbiri içine giren ve birbiriyle ilgili birçok unsuru içinde barındırdığı görülmektedir. Bu ilgilendirmede dilin bütün aşamaları ve çeşitliliğini tiyatro aracılığı ile görebilme imkânını elde etmekteyiz. Çok basit gibi görünen bir olay ve dirimin arkasındaki ifadenin, kendi içinde oluşturduğu bütünlüğü ve derinliği tiyatro aracılığı ile somutlaştırmaktayız. 


\section{Sonuç ve Değerlendirme}

Güzel sanatların tamamını içinde barındıran tiyatro, bu sanatların özel niteliklerini kendi gerçeği ile yeniden sorgulayan bir yapı olmakla birlikte, bu sanatları özelleştiren bir alandır. Heykeltıraşlık, taşa biçim verme, ona yeni bir boyut kazandırma sanatı iken tiyatro, bu sanatı oyuncu üzerinde uygular. Oyuncular, tiyatro sahnesinde rollerinin gereğini yerine getirirken normal hayatlarından ve alışkanlıklarından sıyrılarak yeni bir kimlik ve kişiliğe bürünürler. Yapılan karakter makyajı ile şekil verilen biçimsel görüntünün yanında bu biçimsel görüntüye uygun sözlerle de oyuncu tamamen farklı ve özel bir kimliğe bürünmüş olur. Bu kimlik aynı zamanda kendi dilini ve kültürünü de ortaya koyar. Böylece dil de tıpkı bir taşın biçimlendirilmesi, bir resmin renklendirmesi ve bir müziğin notaya dökülmesi gibi biçimlenir ve forma sokulur.

Tiyatronun güzel sanatların bütün alanlarıyla ilgili olduğu ve bu alanları bütün estetik boyutuyla sahneye aktardığı bilinmektedir. Resim, dans, müzik bunlar arasında sayılabilir. Bütün bu alanların her biri kendi dil ve ifade estetiğini oluşturur.

Tiyatro izlenmek üzere kaleme alınmakla birlikte edebî bir türdür. Diğer edebî türlerde olduğu gibi kurguladığı bir olay veya durumu dil aracılığı ile aktarma çabası içerisindedir. Bu çabayı yerine getirirken oluşturulan metin, kendine özgü ve özel bir yapıyla karşımıza çıkar. Tiyatroda kullanılan dil, hem kuramsal hem de işlevsel bir yapıya bürünür.

Tiyatro metinlerinde dilin bütün aşamalarını birlikte ve bir arada bulmak mümkündür. Diyaloglar aracılığı ile birlikte bir olayı hikâye eden tiyatro metinleri, doğrudan hitap etmeyi esas almanın yanında, lirizm yönünü de ön planda tutar. Bu yüzden tiyatroda konuşma (monolog), hikâye/hitabet ve lirizm bir arada bulunur. Bu dört unsurun sınırlarını birbirinden ayırt etmek mümkün değildir.

\section{Okuma Listesi}

And, M. (1978). “ilköğretimde Tiyatro”. Tiyatro Araştırmaları Dergisi, S. 7, Ankara.

Aynal, S. (1989). Dramatizasyon Yönteminin Yaratıcı Dil Üzerindeki Etkisi. Yayınlanmamış Yüksek Lisans Tezi, Ankara Üniversitesi, Sosyal Bilimler Enstitüsü, Ankara.

Aytaş, G. (2000). Türkçe Öğretiminde Tematik Yaratıcı Drama (Etkinlik ve Uygulamaları). Akçağ Yayınları, Ankara.

Aytaş, G. (2001). "Çocuk ve Tiyatro". Gazi Üniversitesi Kastamonu Eğitim Fakültesi Eğitim Dergisi, C. 9, S. 1, Mart.

Baltacıoğlu, i.H. (1943). "Tiyatro Problemi". Yeni Adam Dergisi, S. 433, s. 8-9

Baltacıoğlu, i. H. (1995). “Okul Tiyatrosu”. Halk Tiyatrosu Dergisi, Yıl: 1, Sayı: 5, Mayıs.

Demirel, Ö. (1999). İlköğretim okullarında yabancı dil öğretimi. Milli Eğitim Basımevi, i̇stanbul.

Gözler, H. F. (1984). Örnekleriyle Türkçe ve Edebiyat Bilgileri. Boğaziçi Yayınları, İstanbul.

Günay, V. D. (2003), Metin Bilgisi. ìstanbul: Multilingual Yayınları, 384 s. 


\section{Kuramsal ve İşlevsel Dil Öğretiminde Tiyatronun Rolü ve Önemi}

Nutku, Ö. (2006). Oyun, Çocuk, Tiyatro, İstanbul: Özgür Yayınları.

Onan, B. (2010). Beynin Bilişsel İşlevleri Üzerine Yapılan Araştırmalar ve Anlambilimine Yansımaları, TÜBARXXVII, Bahar, s. 521-561.

Özertem, T. (1992). Türkiye'de Çocuk Tiyatrosu, Kültür Bakanlığı Yayınları, Eskişehir.

Tekcan, A. ve, i. (2005). Türkçe Kelime Normları. Boğaziçi Üniversitesi Yayınevi.

Tunalı, I. (1971), Sanat Ontolojisi. İstanbul Üniversitesi Fen-Edebiyat Fakültesi Yayınları

Yalçın, A. ve Aytaş, G. (2000). Tiyatro ve Canlandırma Sahneleme Bilgileri. Akçağ Yayınları, Ankara. 